\title{
CHALLENGE BASED LEARNING FOR PATIENT CENTERDERNESS: EDUCATIONAL REFORM
}

\author{
Olivares $\mathrm{S}^{*}$, Jiménez MA, Valencia J, Turrubiates M and Valdez- \\ García J
}

Tecnologico de Monterrey, Escuela de Medicina y Ciencias de la Salud, Mexico

\begin{abstract}
The purpose of this study was to gather recommendations from organizational leaders, faculty, and students as an input to curricular reform for healthcare programs. The method was a qualitative research with a focus group and interviews with 26 leaders, faculty, and students. Focus group participants were leaders who dialogued reflect on the future tasks of healthcare professionals of the future. The data from the focus group was analysed learning environment dimensions. Five themes emerged from the focus groups. Eight leaders from associations, hospitals and medical schools remarked the importance on: 1) patient centered care, emphasis on prevention and well-being, 2) professionalism and identity formation, 4) innovation, research, and technology, 5) leadership for healthcare systems. Interviews showed that biomedical contents develop critical thinking and self-directed learning. Interviewees recommended starting patient care earlier on the program. There was a significant curricular reform to address opportunities and suggestions from participants. Perspectives from different stakeholders helped to develop inter-professional education for five programs. Patient Centeredness is learned from the first year of the programs through challenge-based learning. This approach which started on August 2019 is intended to develop leaders for the improvement of the healthcare systems. Even that scientific and technological advances demand radical change for universities, there are centuries of history that restrain them. At Tecnologico de Monterrey, School of Medicine and Health Sciences an integrated curriculum with challenges for wellness instead of diseases is now a reality.
\end{abstract}

Keywords: Challenge Based Learning, Curriculum design, Patient Centered Care, Leadership, Higher education

\section{Introduction}

Higher education institutions have been conceived as change agents and allies to detonate a better quality of life for individuals and society. Universities have been founded on such transcendent principles that they have been associated with prestige and credibility as a constant for centuries (Beraza \& Rodríguez, 2007). The community of practice of faculty and students has made important contributions to progress and innovation in their regional o national contexts. The impact on health and financial sectors positively correlates with increasing life expectancy and comfort for society

Sociologists agree that universities serve as a meritocratic mechanism for social mobility through occupational allocation of labor positions (Stevens et al., 2008). However, recently it has been questioned the value-added of the university for employment since several informal new jobs are now better economically rewarded than professional position (Brown et al., 2020). According to White (2018), American universities are experiencing financial crises due to the difficulty of increasing their market, which is jeopardizing the future of these institutions. 
An avalanche of changes on the higher education sector demanded authorities to provoke a dramatic curricular reform, considering a fusion among theory and practice and a distinctive pedagogical (Barber et al., 2013). Current trends in higher education, remark that in order to stay relevant and sustainable, institutions need to adjust their courses, curricula, and degree programs to meet learners' needs, as well as the demands of emergent industries and an evolving workforce (e.g., automation, digital literacy, gig economy) (Brown et al., 2020). The COVID-19 pandemic has accelerated those changes.

Since 2012 the New Media Consortium (NMC) established some trends that needed to be considered for curricular reforms. Those trends included: a) a new emphasis should have challenge-based learning and active learning, b) educational paradigms should change to include online education, hybrid learning, and collaborative models (Johnson et al., 2012). Challenge-based learning includes both active learning and a collaborative model since it is an experience where the participants develop solutions that require an interprofessional and creative approach for the development of transversal skills (Olivares et al., 2019). At Tecnologico de Monterrey, in 2019, a new curriculum designed was introduced based on challenges instead of disciplines.

Medicine is one of the oldest professional disciplines to heal people, even since ancient times when palliative care was the only available professional activity. Medical schools have been part of the university since the $\mathrm{X}$ century (Valdez García, 2004). However, its own sector's traditional domination has moved to face constrained centralization (assurance companies, healthcare institutions, regulatory boards), which reduces autonomy, self-regulation, and sense of power to the medical doctors (Coburn, 2006). Then interprofessional collaboration is required to increase patientcentered care, which has shown better clinical practice results in terms of quality and safety offered to the patient (Koehn \& Charles, 2019).

The schools of medicine in Mexico must address the requirements for medical professional tasks of the future. According to the OECD (2019), employers consider that graduates lack generic competences as responsibility, teamwork, and other transversal skills. So, it is urgent to move forward to generate curricular reforms in healthcare professions to couple with the changes that are currently taking place, which is not aligned correctly among the government, healthcare institutions, and government. According to D'Amour \& Oandasan (2005). Interprofessional education creates links among learners, teachers, and professionals (micro level), between teaching and health organizations (meso level), and among systems such as political, socio-economic, and cultural systems (macro level).

These accelerated regulatory, social, and technological changes in the environment demand a versatile doctor able to provide customized patient care, long-life learning, complex challenge solver and critically think about their own actions (Valdez García, 2019). Therefore, it was necessary to inquire about the readiness to evolve the legacy program into an integrated interprofessional curriculum, challenged-based, and patient-centered learning.

\section{Methods}

During 2016, at the School of Medicine and Health Sciences at Tecnologico de Monterrey in Mexico, authorities started a reflection towards a curriculum reform to ensure greater alignment with required 
future skills for healthcare programs. A qualitative design was conducted with a focus group and structured interviews. Focus groups allow exploring different perspectives among several participants and interviews to collect data to gain insights from one individual (Hanson et al., 2011).

The purpose of this study was to gather recommendations from organizational leaders, faculty, and students as input for a curricular reform for healthcare programs.

Participants were six leaders (educational and hospital institutions and accrediting boards), six students, and 12 faculty members. Leaders were individually invited to the focus group to reflect on future trends for medical education and health sciences. The results presented here are from those who agree to participate in the study.

\section{Results}

\section{Focus groups with leaders}

The question for participants was: What will be the leading professional tasks for health professionals of the future, considering social, scientific, and technological trends? Answers were documented following the affinity diagram method (Evans \& Lindsay, 2014). The first step was to brainstorm ideas to answer the question, followed by the categorization of results. Five themes emerged as presented in table 1.

Table 1: Emergent topics to be addressed on the healthcare programs

\begin{tabular}{ll}
\hline Categories & Codes \\
\hline Patient-centered care & Patient relationship (2) \\
& Management of resources \\
Customized medicine
\end{tabular}

Patient centered learning refers to patient care as a person who collaborates with the health team to decide every clinical intervention, considering holistic quality healthcare services aligned patient preferences in every phase of clinical care: patient knowledge, diagnosis, intervention, and monitoring/follow up (Olivares Olivares \& Valdez-García, 2017). Authors include four perspectives on the model: a) human, b) biomedical, c) managerial, and d) entrepreneurial. In a previous study, 
semi-structured interviews were conducted with 55 medical students of three different schools, and qualitative analysis showed that an interpretation based on the classic model that focuses on the autonomy and status of the profession prevails, underestimating the centered patient approach (González et al., 2019).

Promotion of health, disease prevention, and education towards a healthy lifestyle is a trending requirement for healthcare professionals. This holistic or medicine functional approach is oriented to prevent diseases or promote lifestyle changes to reduce risk factors (Scattergood, 2010). Considering that health professionals must take care of other people, curricular reforms also focus on caring about themselves (Abreu et al., 2020). According to Cohen et al. (2009) medical students face identity challenges since the novice role. The authors describe the growing demands of the medical culture, particularly emotional and workload stress burdens, and cognitive-moral development challenges. Humanities, ethical commitment, and social responsibility are then necessary for the new medical programs.

Participants expressed concern about technology trends and healthcare practice for future graduates. This reflection is consistent with Thornton and Russek's report (2019) who predict leaps in artificial intelligence (AI), Virtual Reality, and Augmented Reality with digital identity. This accelerated socialization with technologies demands students' education for innovation, research, and coexist with health technology to solve every day or extraordinary health challenges. An interprofessional approach with the appropriate leadership is suggested to improve and innovate quality and safety in clinical care.

\section{Interviews with the academic community}

Students and faculty members were interviewed to suggest the most significant changes that should be applied to the school's current programs. There were 18 interviews with 12 faculty members and six students whose responses were categorized according to learning environment psychosocial dimensions (personal, social, and organizational). Material dimension includes physical spaces, facilities, and infrastructure (Gruppen et al., 2019). Table 2 shows the synthesis of the interviews.

Table 2. Data from interviews

\begin{tabular}{|c|c|c|}
\hline & Strengths & Opportunities \\
\hline Personal & $\begin{array}{l}\text { Self-directed learning } \\
\text { Critical thinking and analysis }\end{array}$ & $\begin{array}{l}\text { Increase innovative ideas } \\
\text { Feedback and assessment } \\
\text { Excess of contents }\end{array}$ \\
\hline Social & $\begin{array}{l}\text { Clinical practice (2) } \\
\text { Relationship with patients } \\
\text { Learning communities } \\
\text { Faculty experts } \\
\text { Collaboration with residents and } \\
\text { faculty }\end{array}$ & $\begin{array}{l}\text { Lack of communication among faculty members } \\
\text { Late contact with patients ( } 5 \text { th year) ( } 3 \text { ) } \\
\text { Limited human orientation with patients } \\
\text { More participation in projects }\end{array}$ \\
\hline Organizational & $\begin{array}{l}\text { Program structure } \\
\text { International experience } \\
\text { Pedagogical practices (PBL) } \\
\text { Small groups }\end{array}$ & $\begin{array}{l}\text { There is no congruence among course instructed by } \\
\text { different teachers. }\end{array}$ \\
\hline
\end{tabular}


$\begin{array}{lll}\text { Material } & \text { Simulation labs } & \text { More lab practices }\end{array}$

As the personal dimension, Gruppen et al. (2019) recommend vitality, well-being, purpose, development, and identity formation. Both faculty members and students considered the importance of this topics for the curricular reform. Students also recognize that favors critical thinking and selfdirection. However, they might be excessive besides medical topics.

Participants agreed that clinical practices on starting on their fifth year develop relationships with patients, residents, and faculty for the social dimension. The dense interconnections from the academic community, patients, and hospital staff are part of universities's social role (Stevens et al., 2008). The human contact with actual patients occurs until the 5th year when students mentioned being motivated by this interaction. Faculty members consider that it is late for students to integrate doctor-patient relation skills. The curriculum innovation in medical education is significantly expanding in health systems to be shifted to a patient centered approach (Pelzang, 2010; Domenco et al., 2012). This approach contrasts with the medical doctor's traditional dominances, the protagonist in the doctor-patient relationship (Coburn, 2006).

There were some mentions regarding the organizational dimension. Even that participants considered an adequate program structure. There are opportunities for collaboration among faculty members. Additionally, both groups mentioned international experiences and participation in public and private hospitals, which develops skills to manage situations in different contexts.

\section{Conclusions}

The demand in medical education is to educate future professionals who recognize the values, preferences, and needs expressed by the patient as part of their professional identity (Gerteis et al., 1993). Information technology and virtual or real contexts are part of the organizational and material environment that need to be blended with education.

The results previously presented in this study were used as an input for the new curriculum design for healthcare programs at Tecnologico de Monterrey. It was decided to introduce Challenge Based Learning (CBL) for Patient Center Centeredness for Physician and Surgeon (MD), Nutrition and Wellness, Clinical Psychology, Biosciences, and Dentistry bachelor programs. Challenge Based Learning has the purpose of addressing real complex problems from multiple perspectives. Collaboration among faculty and students from different disciplines is the proposal for this curricula reform. Challenges from the first year and a half are oriented to prevention and wellness for individuals and society. Clinical experiences are covered since year one to prevent diseases and timely detect potential risks on health.

Even that scientific and technological advances demand radical change for universities, there are centuries of history that restrain them. At Tecnologico de Monterrey, School of Medicine and Health Sciences, an integrated curriculum with challenges to educate leaders is now implementing. Maybe this transformation inspires other institutions to educate for the wellness of the patient. 


\section{References}

Abreu, L., Valdez-García, J., Esperón, R., Olivares, S. (2020). El reto del COVID-19 respecto a la responsabilidad social de las escuelas de medicina: nuevas perspectivas profesionales y humanas. Gaceta Médica de México (156), 311-316.

Barber, M., Donnelly, K., \& Rizvi, S. (2013). An avalanche is coming: Higher education and the revolution ahead. Institute for Public Policy Research.

Beraza, J. M., \& Rodríguez, A. (2007). La evolución de la misión de la universidad. Revista de Dirección y Administración de Empresas (14).

Brown, M., McCormack, M., Reeves, J. D., Brooks, C., \& Grajek, S. (2020). 2020 EDUCAUSE Horizon Report Teaching and Learning Edition. Louisville, CO: EDUCAUSE.

Coburn, D. (2006). Medical dominance then and now: critical reflections. Health Sociology Review, 15(5), 432-443.

Cohen, M., Kay, A., Youakim, J., \& Balaicuis, J. (2009). Identity Transformation in Medica. American Journal of Psychoanalysis (69), 43-52.

D'Amour, D., \& Oandasan, I. (2005). Interprofessionality as the field of interprofessional practice and interprofessional education: An emerging concept. Journal of Interprofessional Care, 1, 8 - 20.

Elliott, V. (2018). Thinking about the Coding Process in Qualitative Data Analysis. The Qualitative Report, 23(11), 2850-2861.

Evans, J., \& Lindsay, W. (2014). Administración y control de la calidad. México: Cengage.

Gerteis, M., Edgman-Levitan, J., \& Delbanco, T. (1993). Through the Patient's Eyes: Understanding and Promoting Patient-Centered Care. San Francisco CA: Jossey-Bass.

González, P., Olivares, S., \& Fouquet, A. (2019). La visión de los estudiantes de medicina sobre su profesión: obstáculos para la transición a la perspectiva centrada en el paciente. Educación Médica. doi: 10.1016/j.edumed.2019.09.006

Gruppen, L. D., Irby, D. M., Durning, S., \& Maggio, L. A. (2019). Conceptualizing Learning Environments in the Health Professions. Academic Medicine, 94(7), 969-974.

Hanson, J. L., Balmer, D. F., \& Giardino, A. P. (2011). Qualitative Research Methods for Medical Educators. Academic Pediatrics CADEMIC PEDIATRICS 2011, 11, 375-386.

Johnson, L., Adams, S., \& Cummins, M. (2012). The NMC Horizon Report: 2012 Higher Education Edition. Austin, Texas: The New Media Consortium.

Koehn, M. L., \& Charles, S. C. (2019). A delphi study to determine leveling of the Interprofessional Core Competencies for four levels of interprofessional practice. Medical Science Educator, 29, 389398.

OECD. (2019). Higher Education in Mexico: Labour Market Relevance and Outcomes, ,. Higher Education .

Olivares Olivares, S. L., \& Valdez-García, J. E. (2017). Aprendizaje Centrado en el Paciente: Cuatro perspectivas para un aprendizaje integral. México: Editorial Médica Panamericana.

Olivares, S. L., Adame, E., Treviño, J. I., López, M. V., \& Turrubiates, M. L. (2019). Action learning: challenges that impact employability skills. Higher Education, Skills and Work-Based Learning.

Scattergood, D. (2010). Self-care Essential Extras: An Integration of Holistic Nursing, Functional Medicine, and Health Coaching to Promote Therapeutic Lifestyle Change and Decrease Chronic Disease. Holistic Nursing Practice, 24(5), 294-300.

Stevens, M. L., Armstrong, E. A., \& Arum, R. (2008). Sieve, Incubator, Temple, Hub: Empirical and Theoretical Advances in the Sociology of Higher Education. Annual Review of Sociology, 34, 127151. 
Thornton, J., Russek, H., \& O'Neil, T. (2019). Turn and Face the Strange: Changes impacting the future of employment in Canada. Canada: Brookfield Institute.

Valdez García, J. E. (2004). Salerno: la primera escuela de Medicina. AVANCES, 37-39.

White, R. H. (2018). Report on the Future of Higher Education. Oklahoma City, Oklahoma: OSRE. 